\title{
Sistemática bioquímica de Menticirrhus americanus e Menticirrhus littoralis (Teleostei: Perciformes: Sciaenidae)
}

\author{
Vicente P. F. CASSANO* \& José A. LEVY
}

\begin{abstract}
Laboratório de Bioquímica Marinha, Departamento de Química
\end{abstract}
Fundação Universidade do Rio Grande

(Caixa Postal 474, 96.200 Rio Grande, RS)

- Abstract: Populations of two congeneric species of southwestern Atlantic sciaenid fish, Menticirhus americanus and Menticimhus littoralis, analysed electrophoretically to detect isoenzyme variability, showed very little genetic variation and a moderately high similarity in their allelic composition. A total of 22 alleles encoded by 17 loci were observed. Interspecific variability were found for the loci G6pdh-A, G6pdh-B, Hbdh-B, Mdh-B and Sod-A. Intraspecific variation was observed only for Mdh-B in $M$. littoralis. The genetic similarity between $M$. americanus and $M$. littoralis (INEI +0.76 ) is congruent with the high level of morphological similarity showed by these two congeneric species.

- Descriptors: Biochemical systematics, Fishes, Menticirrhus americanus, Menticirrhus littoralis, Sciaenidae, Electrophoresis, Isoenzymes, South coast: Brazil.

- Descritores: Sistemática bioquímica, Peixes, Menticirrhus americanus, Menticirrhus littoralis, Sciaenidae, Eletroforese, Isoenzimas, Costa sul: Brasil.

\section{Introdução}

O gênero Menticirrhus é constituído por nove espécies de peixes marinhos, com distribuição nas regiōes tropicais e temperadas. Seis espécies ocorrem a leste do Oceano Pacífico e três a oeste do Oceano Atlântico (Chao, 1978).

Das espécies do Atlântico Sul, Menticirrhus americanus (Linnaeus, 1758) e Menticirrhus littoralis (Holbrook, 1855) sāo encontradas no litoral brasileiro. São peixes demersais de tamanho médio, bentófagos de epifauna e ocorrem em águas de pouca profundidade das regiōes costeiras e estuarinas (Menezes \& Figueiredo, 1980; Jardim, 1988).

A identificação destas duas espécies baseia-se, principalmente, no tamanho das escamas da região peitoral em relação ao da região situada à linha lateral, no padrão de coloração e no comprimento das nadadeiras peitorais em relação às pélvicas (Chao, 1978; Menezes \& Figueiredo, 1980). Outros caracteres morfométricos,

(*) Bolsista do CNPq. Department of Biology, University of California at Los Angeles, 405 Hilgard Avenue. Los Angeles, California, 90024 - 1606, U.S.A. rotineiramente utilizados para a identificação de peixes, não discriminam estas duas espécies que apresentam grande semelhança morfológica.

A aplicação de métodos bioquímicos no estudo das macromoléculas informacionais em organimos estreitamente relacionados, tem produzido informaçōes relevantes e, em certos casos, crítica para o estabelecimento de relaçōes filogenéticas (Dobzhansky et al., 1977). Dentre as técnicas mais empregadas, o fracionamento eletroforético de isoenzimas em géis destaca-se pela simplicidade, rapidez e reduzido custo em relação às técnicas de seqüenciamento, e tem servido para estimar a diferenciação genética entre espécies de diversos tipos de organismos. Vários estudos com marcadores genéticos em peixes têm procurado inferir a estrutura gênica das populaçōes (Grant, 1985; Gyllensten, 1985); estabelecer a relação entre variabilidade morfológica e genética (McAndrew et al., 1982; Hadfield et al., 1979); definir as relaçōes filogenéticas (Hudom \& Guderley, 1984) e propor evidências de isolamento reprodutivo em espécies simpátricas (Sole-Cava et al., 1983; Ferguson \& Mason, 1981). Nos últimos anos, os métodos eletroforéticos têm-se mostrado - de grande ultilidade e têm sido preconizados para a análise genética dos recursos pesqueiros (FAO/UNEP, 1981). 
O objetivo deste trabalho é verificar e estimar a variabilidade genética em populaçōes de duas espécies do gênero Menticirrhus do litoral sul-brasileiro através do emprego da eletroforese de isoenzimas.

\section{Material e métodos}

Os exemplares utilizados foram capturados pelo N/Oc. "Atlântico Sul", em 1984, na regiāo de pesca de Rio Grande, RS, entre $30^{\circ} 40^{\prime}$ e $33^{\circ} 28^{\prime} \mathrm{S}$, por meio de arrasto de fundo com redes de porta.

Foram analisados dez exemplares adultos, de ambos os sexos de cada espécie. Este número amostral está de acordo com Nei (1978) e com Gorman \& Renzi (1979) para o estudo das relações interespecíficas.

Amostras de músculo e fígado foram retiradas de cada exemplar e homogeneizadas em tampão tris- $\mathrm{HCl} 0,02 \mathrm{M}$, pH 7,5 na proporçāo 1:1 de peso/volume. O homogeneizado foi centrifugado por $\mathbf{2 0}$ minutos a $\mathbf{2 0 . 0 0 0}$ $\mathrm{rpm}, \mathrm{em}$ centrífuga refrigerada. O sobrenadante obtido foi aplicado sobre membranas de acetato (Cellogel-Chemetron) ou sobre géis de poliacrilamida 7\% e submetido a eletroforese a $5^{\circ} \mathrm{C}$.

As enzimas ensaiadas com os respectivos números de classificação, os tecidos empregados, bem como as condiçōes da corrida eletroforética utilizadas para a análise das populaçōes, estão apresentadas na Tabela 1. As soluçōes empregadas para a revelação da atividade enzimática foram as recomendadas por Brewer, $1970 \mathrm{e}$ Shaw \& Prasad, 1970. Os produtos alélicos foram considerados expressão do mesmo alelo em um mesmo gene estrutural quando apresentaram idêntica mobilidade eletroforética sob às mesmas condiçōes de corrida (Dobzhansky et al., 1977). O sistema de nomenclatura para os loci e alelos é o proposto por Allendore \& Utter (1979). A mobilidde relativa dos produtos alélicos dos loci polimórficos foi determinada tendo como referência o alelo de maior freqüência na amostra de $M$. americanus ao qual atribui-se o valor de 100.

Tabela 1. Sistemas enzimáticos estudados, tecidos e tampões utilizados

\begin{tabular}{|c|c|c|c|c|}
\hline Enzimas & & EC & Tecido & Tampōes \\
\hline Alcool-des idrogenase & $\mathrm{ADH}$ & EC 1.1.1.1 & fígado & I \\
\hline Aspartato-aminotransferase & AAT & EC 2.6.1.1 & fígado & II \\
\hline Enzima Mática & ME & EC 1.1 .1 .40 & músculo & II \\
\hline Esterase & EST & EC 3.1 .1 .1 & músculo & III \\
\hline Glucose-6-fosfato-desidrogenase & G6PDH & EC 1.1.1.49 & fígado & I \\
\hline Glutanato-desidrogenase & GDH & EC 1.4 .1 .3 & fígado & 1 \\
\hline Hidrox ibut irato-des idrogenase & HBDH & EC 1.1.1.31 & fígado & I \\
\hline Isocitrato-des idrogenase & IDH & EC 1.1.1.42 & fígado & II \\
\hline Malato-des idrogenase & MDH & EC 1.1.1.37 & fígado & III \\
\hline Superóxido-dismutase & SOD & EC 1.15.1.1 & músculo & III \\
\hline Xant ina-desidrogenase & $\mathrm{XDH}$ & EC 1.2.1.37 & fígado & 1 \\
\hline
\end{tabular}

I - 0,5 M tris-verseno-borato pH 8.0 (Shaw \& Prasad, 1970); II - veronal pH 8.7 (Brewer, 1970); III - tris-citrato pH 8.65 (Poulik, 1957) 


\section{Resultados}

Foram detectados vinte e dois alelos, atribuíveis a dezessete loci. Três diferentes padrões de distribuição alélica nos loci gênicos foram encontrados: 1) as espécies exibem os seguintes loci monomórficos para o mesmo alelo: Adh-A, Aat-A, Aat-B, Est-A, Est-B, Est-C, Gdh-A, Hbdh-A, Idh-A, Mdh-A, Me-A e Xdh-A; 2) as espécies compartilham o mesmo alelo no locus dialélico Mdh-B e $M$. littoralis apresenta um segundo alelo exclusivo; 3) os loci G6pdh-A, G6pdh-B, Hbdh-B e Sod-A, são diagnósticos para as duas espécies de Menticirnhus examinadas. Todos os produtos alélicos revelados apresentaram migração anódica nas condiçōes experimentais empregadas, com exceção do produto do alelo 100 do locus Aat-1, que migra no sentido do cátodo.

As freqüências alélicas para os locus gênicos examinados, resumidos na Tabela 2 , foram empregadas para o cálculo dos índices de Identidade Genética de Nei (1972) e de Similaridade Genética de Thorpe (1979), respectivamente, 0,763 e 0,761 .

Tabela 2. Freqüências alélicas para dezessete loci em populações de Menticirrhus americanus (a) e Menticirnhus littoralis (b)

\begin{tabular}{lrcc}
\hline Loci & Alelos & (a) & (b) \\
\hline Adh-A & 100 & 1,0 & 1,0 \\
Aat-A & 100 & 1,0 & 1,0 \\
Aat-B & 100 & 1,0 & 1,0 \\
Est-A & 100 & 1,0 & 1,0 \\
Est-B & 100 & 1,0 & 1,0 \\
Est-C & 100 & 1,0 & 1,0 \\
Gdh-A & 100 & 1,0 & 1,0 \\
G6pdh-A & 100 & 1,0 & - \\
& 70 & - & 1,0 \\
G6pdh-B & 100 & 1,0 & - \\
& 65 & - & 1,0 \\
Hbdh-A & 100 & 1,0 & 1,0 \\
Hbdh-B & 100 & 1,0 & - \\
& 80 & - & 1,0 \\
Idh-A & 100 & 1,0 & 1,0 \\
Mdh-A & 100 & 1,0 & 1,0 \\
Mdh-B & 100 & 1,0 & 0,94 \\
& 85 & - & 0,06 \\
Me-A & 100 & 1,0 & 1,0 \\
Sod-A & 100 & 1,0 & - \\
& 80 & - & 1,0 \\
Xdh-A & 100 & 1,0 & 1,0
\end{tabular}

\section{Discussão}

A análise dos resultados obtidos revela a grande semelhança genética entre as duas espécies congenéricas de Menticirrhus. Doze, dos dezessete loci examinados, são idênticos nas amostras das populaçōes estudadas, um locus, Mdh-B, apresenta certa semelhança, já que as duas espécies compartilham um dos alelos, sendo o segundo alelo exclusivo para $M$. littoralis e apenas quatro loci são diagnósticos. Loci diagnósticos são definidos por Bucklin \& Hedgecock (1982) como loci que apresentam alelos diferentes fixados para amostras de populaçōes de diferentes espécies. Tais loci teriam resultado da fixação gradual de alelos raros na população original, por pressōes seletivas direcionais diferentes, ou pela ação da deriva genética sobre populações formadas originalmente por pequeno número de indivíduos (Mayr, 1970). A observação de loci diagnósticos comprova a inexistência de fluxo gênico entre as populaçōes destas duas espécies simpátricas de peixes demersais, evidenciando o isolamento reprodutivo (Ayala, 1983).

O locus Mdh-B, com o alelo 100, comum às duas espécies e o alelo 85, exclusivo para a população de $M$. littoralis, encontra-se em processo de diferenciação que tende a torná-lo um locus diagnóstico. O tempo necessário para que esta diferenciaçāo se complete vai depender do grau de conservatividade do locus.

Os loci monomórficos para o mesmo alelo nas duas espécies de Menticirrhus são loci que, por efeito do acaso, por serem mais conservativos ou por terem sido submetidos às mesmas pressōes seletivas (Lucotte \& Lefebvre, 1980; Avise, 1977), mantiveram constantes e inalteradas as freqüências de seus alelos desde o momento da separação da populaçāo original em vários demes. Thorpe (1979) sugere que a identidade genética entre a maioria das espécies congenéricas situa-se entre os valores de 0,25 e 0,85 . O valor obtido para tal índice entre $M$. americanus e $M$. littoralis (INei $=0,76)$, sugere que estas espécies apresentam similaridade genética moderadamente elevada.

\section{Conclusões}

A análise eletroforética de Menticirrhus americanus e Menticirrhus littoralis revela que seus genomas acumularam um número de mutaçōes insuficientes para produzir diferenciaçāo significativa dos loci gênicos estruturais codificadores das isoenzimas analisadas, o que explicaria a elevada similaridade genética. $\mathrm{O}$ estudo comparativo da morfologia externa destas duas espécies de cienídeos, por outro lado, evidencia sua grande semelhança fenotípica.

Os resultados indicam que o evento cladogênico separador da população ancestral em duas sub-populaçōes, e a subseqüente evolução das linhagens que deram origem às duas espécies atuais de Menticirrhus, ocorreram de tal modo que as pequenas modificaçōes da morfologia foram acompanhadas por igualmente pequena diferenciação isoenzimática. Existe, portanto, congruência entre a evoluçāo genotípica e fenotípica de $M$. americanus e $M$. littoralis. 


\section{Resumo}

Populaçōes de duas espécies congenéricas de peixes cienídeos do Atlântico Sul-Oriental, Menticirrhus americanus e Menticirrhus littoralis, analisados eletroforeticamente para detectar a variabilidade isoenzimática, mostraram muito pouca variação genética e uma moderadamente alta similaridade em sua composição alélica. Um total de 22 alelos constituídos por 17 loci foram observados. Variabilidade interespecífica foi encontrada para os loci G6pdh-A, G6pdh-B, Hbdh-B, Mdh-B e Sod-A. Variaçāo intraespecífica foi observada somente para Mdh-B em $M$. littoralis. A similaridade genética entre $M$. americanus e $M$. littoralis (INEI $=0,76$ ) é congruente com o alto nível de similaridade morfológica mostrado por estas duas espécies congenéricas.

\section{Agradecimentos}

Agradecemos a Leo Lacerda e Maria Regina Casartelli pela colaboração e à Dra Anna Emília A. de M. Vazzoler e Dr. Antonio Sole-Cava pela leitura crítica e sugestões apresentadas. Este trabalho contou com o auxilio do CNPq (Proc. 40.5654/83) e FURG.

\section{Referências bibliográficas}

ALLENDORF, F. W. \& UTTER, F. M. 1979. Population genetics. In: Hoar, S. et al., eds Fish physiology. New York, Academic Press. v.8, p.407-454.

AVISE, J. C. 1977. Genetic differentiation during speciation. In: Ayala, F. J., ed. Molecular evolution. Sunderland, Sinauer Assoc. p.106-122.

AYALA, F. J. 1983. Enzymes as taxonomic characteres. In: Oxford, G. S. \& Rollinson, D., eds Protein polymorphism: adaptative and taxonomic significance. London, Academic Press. (Systematics Association Special Volume n²4).

BREWER, G. J. 1970. An introduction to isozymes techniques. New York, Academic Press.

BUCKLIN, A. \& HEDGECOCK, D. 1982. Biochemical genetic evidence for a third species of Metridium (Coelenterata: Actiniaria). Mar. Biol., 66:1-7.

BUTH, D. G. 1983. Duplicate isozyme loci in fishes: origins, distribution, phyletic consequences, and locus nomenclature. In: Isozymes. New York, Alan R. Liss. p. 381-400.

CHAO, L. N. 1978. A basis for classifying western Atlantic Sciaenidae (Teleostei: Perciformes). Tech. Rept natn. mar. Fish. Serv. U.S., Circ., (415):1-64.
DOBZHANSKY, T. G.; AYALA, F. J.; STEBBINS, G. L. \& VALENTINE, J. W. 1977. Evolution. San Francisco, W. H. Freeman.

FAO/UNEP. 1981. Conservation of the genetic resources of fish: problems and recommendations. Report of the Expert Consultation on the Genetic Resources of Fish. Rome, 9-13 June 1980. FAO Fish. tech. Pap., (217):1-43.

FERGUSON, A. \& MASON, F. M. 1981. Allozyme evidence for reproductively isolated sympatric populations of brown trout Salmo trutta L. in Louch Melvin, Ireland. J. Fish Biol., 18:629-642.

GORMAN, G. C. \& RENZI, J. 1979. Genetic distance and heterozygosity estimates in electrophoretic studies: effects of sample size. Copeia, (2):242-249.

GRANT, W. S. 1985. Biochemical genetic stock structure of the southern African enchovy, Engraulis capensis Gilchrist. J. Fish Biol., 27:23-29.

GYLLENSTEN, U. 1985. The genetic structure of fish: differences in the intraspecific distribution of biochemical genetic variation between marine, anadromous, and freshwater species. J. Fish Biol., 26:691-699.

HADFIELD, A. J.; IVANTSOFF, V. \& JOHNSTON, P. G. 1979. Clinal variation in electrophoretic and morphological characters between two nominal species of the genus Pseudomugil (Pisces: Atheriniformes: Pseudomugilidae). Aust. J. mar. Freshw. Res., 30:375-386.

HUDON, J. \& GUDERLEY, H. 1984. An electrophoretic study of the phylogenetic relationships among four species of sticklebacks (Pisces: Gasterosteidae). Can. J. Zool., 62:2313-2316.

JARDIM, L. F. A. 1988. Sinopse das espécies de Menticirnus Gill, 1861 (Osteichthyes, Sciaenidae) do Atlântico Ocidental. Revta bras. Zool., 5(2):179-187.

LUCOTTE, G. \& LEFEBVRE, J. 1980. Distances electrophorétiques entre les cinq espéces de babouins du genre Papio basées sur les mobilités des proteines et enzimes seriques. Biochem. Syst. Ecol., 5:61-63.

MAYR E. 1970. Populations, species and evolution: an abridgement of animal species and evolution. Cambridge, Harvard University Press. 453p.

MCANDREW, B. J.; WARD, R. D. \& BEARDMORE, J. A. 1982. Lack of relationship between morphological variance and enzyme heterozygosity in the plaice Pleuronectes platessa. Heredity, 48:117-125. 
MENEZES, N. A. \& FIGUEIREDO, J. L. 1980. Manual de peixes marinhos do sudeste do Brasil. IV. Teleostei. (3). São Paulo, Museu de Zoologia da Universidade de São Paulo. 96p.

NEI, M. 1972. Genetic distance between populations. Am. Naturalist, 106:283-291.

1978. Estimation of average heterozygosity and genetic distance from a small number of individuals. Genetics, 89:583-590.

POULIK, M. D. 1957. Starch gel electrophoresis in a discontinuous system of buffers. Nature, Lond., 180:1477-1479.
SHAW, C. R. \& PRASAD, R. 1970. Starch gel electrophoresis of enzymes - a compilation of recipes. Biochem. Genetics, 4:297-320.

SOLE-CAVA, A. M.; VOOREN, C. M. \& LEVY, J. A. 1983. Isozyme differentiation of two sibling species of Squatina (Chondrichthyes) in south Brazil. Comp. Biochem. Physiol., 75B:355-358.

THORPE, J. P. 1979. Enzyme variation and taxonomy: the estimation of sampling errors in measurements of interspecific genetic similarity. Biol. J. Linn. Soc., 11:369-386.

(Recebido em 02-02-89; aceito em 19-02-90) 